\title{
INFRARED SPECTROSCOPY AS A PROBE FOR THE DEVELOPMENT OF SECONDARY STRUCTURE IN THE AMINO-TERMINAL SEGMENT OF ALAMETHICIN
}

\author{
Ch. PULLA RAO, R. NAGARAJ, C. N. R. RAO and P. BALARAM" \\ Solid State and Structural Chemistry Unit and Molecular Biophysics Unit, Indian Institute of Science, Rangalore 560012, India
}

\section{Introduction}

Peptides containing $\alpha$-aminoisobutyryl (Aib) residues have been shown to adopt well-defined structures in solution, by ${ }^{1} \mathrm{H}$ NMR methods [1]. Theoretical studies suggest that the presence of geminal methyl substituents at $\mathrm{C}^{\alpha}$ imposes severe restrictions on the conformations accessible to Aib residues [2,3]. Single crystal X-ray diffraction studies of Z-Aib-Pro-NHMe [4],Z-Aib-Pro-Aib-Ala-OMe [5] and Tosyl-(Aib) $)_{5}$-OMe [6] have clearly established the tendency of Aib residues to adopt $3_{10}$ helical conformations and to initiate the formation of type III $\beta$ bends, stabilised by $4 \rightarrow 1$ intramolecular hydrogen bonds. Interest in the stereochemistry of Aib containing peptides, stems from the fact that alamethicin $[7,8]$ and the related polypeptide ionophores antianioebin [9], emmerimicin [10], suzukacillin [11] and trichotoxin [12] contain high proportions of Aib residues. Here, we report the results of an infrared spectroscopic study of synthetic alamethicin fragments and demonstrate the development of a $3_{10}$ helical structure at the amino-terminus of the antibiotic.

\section{Experimental procedures}

The peptides were synthesised by solution phase methods using DCC mediated couplings. Specific pro-

Abbreviations: Aib, a-aminoisobutyric acid; Z, benzyloxycarbonyl; Tosyl, p-toluenesulfonyl; DCC, dicyclohexylcarbodiimide

* To whom correspondence should be addressed cedures have been described in [1]. All compounds were chromatographically homogeneous, by thin-layer chromatography on silica gel and yielded 100 and $270 \mathrm{MHz}{ }^{1} \mathrm{H}$ NMR spectra fully consistent with their structures. Infrared spectra were recorded on a Perkin Elmer 580 spectrometer. Spectra were recorded in chloroform and carbon tetrachloride using peptide at $5 \times 10^{-3} \mathrm{M}$ and $1 \times 10^{-4} \mathrm{M}$, respectively. The solvents were dried and distilled immediately before use. For studies in $\mathrm{CHCl}_{3}$ a variable pathlength cell with $\mathrm{NaCl}$ windows was used and the pathlengths employed were $3.4 \mathrm{~mm}$ and $2.2 \mathrm{~mm}$. Spectra in $\mathrm{CCl}_{4}$ were recorded using a $10 \mathrm{~cm}$ pathlength, fused silica cell. Integral band intensities were calculated as in [13].

\section{Results and discussion}

Figure 1 shows the $3250-3500 \mathrm{~cm}^{-1}$ region of the infrared spectra of the peptides Z-Aib-Pro-OMe (I), Z-Aib-Pro-NHMe (II), Z-Aib-Pro-Aib-OMe (III), Z-Aib-Pro-Aib-Ala-OMe (IV), Z-Aib-Pro-Aib-Ala-Aib$\mathrm{OMe}(\mathrm{V})$ and Z-Aib-Pro-Aib-Ala-Aib-Ala-OMeVI) in dilute solution in $\mathrm{CHCl}_{3}$. The band at $3430-3440 \mathrm{~cm}^{-1}$ corresponds to the free $\mathrm{NH}$ stretching frequency $\left(\nu_{\mathrm{N}-\mathbf{H}}\right.$ free) while the bands between $3330-3370 \mathrm{~cm}^{-1}$ correspond to hydrogen-bonded $\mathrm{NH}$ groups $\left(\nu_{\mathrm{N}-\mathrm{H}}\right.$ bonded). A striking feature in fig. 1 is the almost constant intensity of the $\nu_{\mathrm{NH}}$ free while the $\nu_{\mathrm{N}-\mathrm{H}}$ bonded increases in intensity, with increasing length of the peptide chain. This suggests that while the Aib [1] NH group is free in all the peptides, the remaining amide $\mathrm{NH}$ groups are involved in intramolecular hydrogen bonding. The peak positions, 


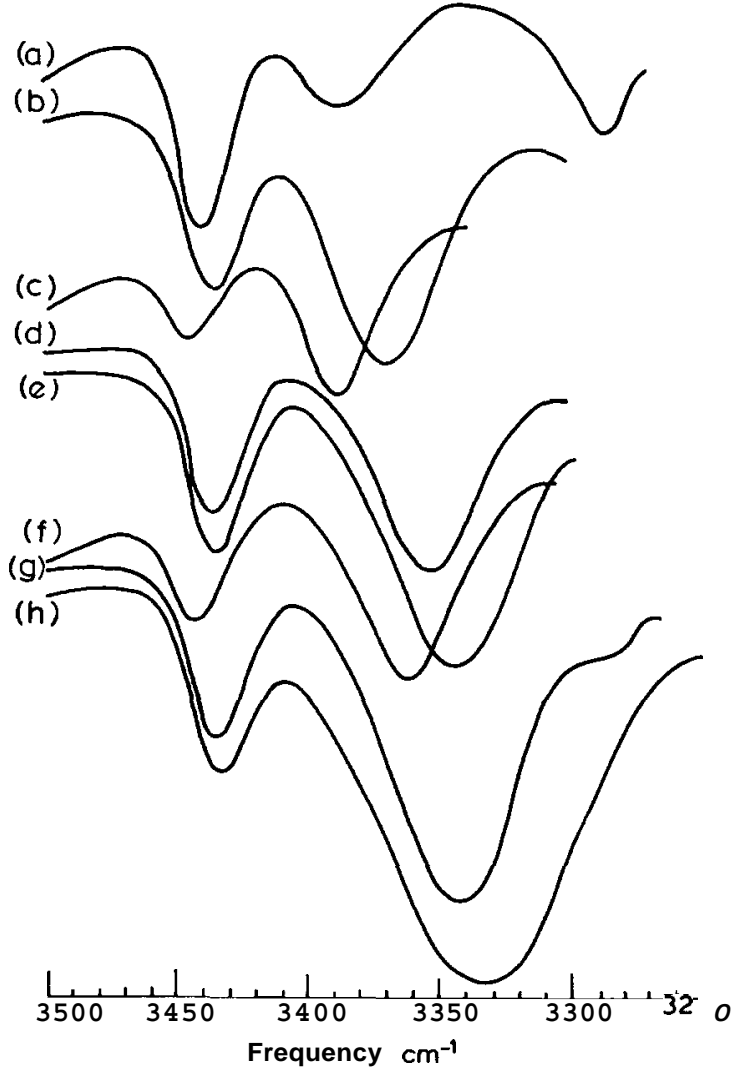

Fig.1. Infrared spectra in the region $3250-3500 \mathrm{~cm}^{-1}$ for the peptides in solution. (a) I, CHCI; (b) II, $\mathrm{CHCl}_{3}$; (c) II, $\mathrm{CCl}_{4}$; (d) III, $\mathrm{CHCl}_{3}$; (e) IV, $\mathrm{CHCl}_{3}$; (f) IV, $\mathrm{CCl}_{4}$; (g) V, $\mathrm{CHCl}_{3}$; (h) VI-L, $\mathrm{CHCl}_{3}$.

widths at half heights $\left(\Delta \nu_{1 / 2}\right)$ and the integral band intensities for the peptides examined in this study are listed in table 1.

${ }^{1} \mathrm{H}$ NMR studies in $\mathrm{CDCl}_{3}$ have clearly established that Z-Aib-Pro-Aib-OMe (III) and Z-Aib-Pro-Aib-AlaOMe (IV) contain 1 and 2 hydrogen-bonded $\mathrm{NH}$ groups, respectively [1]. Further, the tetrapeptide IV has been shown to have two consecutive $\beta$-turns in the solid state, stabilised by two intramolecular hydrogen bonds involving the Aib [3] $\mathrm{NH}$ and Ala [4] NH groups. These results suggest that the conformations obtained in the solid state are maintained in solution for the relatively inflexible Aib containing peptides. Consequently it is a reasonable assumption that the conformation of the tetrapeptide IV, observed by IR methods in dilute $\mathrm{CHCl}_{3}$ solution, also corresponds to the consecutive $\beta$-turn or incipient $3_{10}$ helical structure. Using a value of 2 hydrogen bonds for IV, the observed intensities of the $3330-3370 \mathrm{~cm}^{-1}$ band for the other peptides yield, 1 intramolecular hydrogen bond in II and III, 3 hydrogen bonds in V and 4 hydrogen bonds in VI. The value obtained for II and III are in excellent agreement with the results of X-ray [4] and 'H NMR studies [1], respectively. The infrared studies have been carried out in $\mathrm{CHCl}_{3}$ at $4.5-5 \times 10^{-3} \mathrm{M}$, when intermolecular associations are likely to be minimal. However, in order to establish this conclusively the peptides II, III, IV and V were studied at significantly lower concentrations in $\mathrm{CCl}_{4}\left(1 \times 10^{-4} \mathrm{M}\right)$. The spectra obtained in $\mathrm{CCl}_{4}$ were almost identical in relative band intensities to the $\mathrm{CHCl}_{3}$ spectra (see fig. $1 \mathrm{c}, \mathrm{f})$. The results are summarised in table 1 .

Further support for our contention that the $3330-3370 \mathrm{~cm}^{-1}$ band corresponds to a 10 atom hydrogen structure, comes from our studies on model Aib containing peptides. It was observed that this infrared band occurs only in tripeptide esters and higher peptides which are capable of forming 0-turns but not in dipeptide esters, which cannot form the 10 atom hydrogen bond. Infrared studes of Ac-AibNHMe also suggest that structures involving 5 atom $\left(\mathrm{C}\right.$,) and 7 atom $\left(\mathrm{C}_{7}\right)$ hydrogen bonded rings are present in $\mathrm{CCl}_{4}$ [14]. These conformations have been suggested earlier for acetyl-amino acid-methylamides $[15,16]$. An interesting feature of fig.1 is the weak band at $3385 \mathrm{~cm}^{-1}$ observed for Z-Aib-Pro-OMe (I). In $\mathrm{I}$, the 10 atom hydrogen bond and the $\mathrm{C}_{7}$ structure are both not possible. The $3385 \mathrm{~cm}^{-1}$ peak must therefore arise due to the formation of a $\mathrm{C}_{5}$ structure (fig.2a) or the 8 atom hydrogen bonded conformation, shown in fig.2b. It may be noted that the latter requires a cis Aib-Pro bond. The low intensity may be due to the small fraction of molecules populating the hydrogen bonded state and also due to the reduced strength of the 5 or 8 atom hydrogen bonds relative to the 10 atom hydrogen bond. Broad, weak bands at $3395 \mathrm{~cm}^{-1}$ and $3400 \mathrm{~cm}^{-1}$ were also observed in $\mathrm{CHCl}_{3}$ for the model dipeptides Z-Aib-Aib-OMe and Z-Aib-Ala-OMe, which can in principle, form $\mathrm{C}_{5}$ or $\mathrm{C}_{7}$ structures. These results suggest that the $\mathrm{C}_{5}$ and $\mathrm{C}_{7}$ forms occur in non-polar media for molecules which cannot form $\beta$-turns, stabilised by 10 atom hydrogen bonds. 
Table 1

Infrared spectral parameters for alamethicin fragments

\begin{tabular}{|c|c|c|c|c|c|c|c|c|c|c|}
\hline \multirow[t]{2}{*}{ Peptide $^{a}$} & \multirow[t]{2}{*}{ Solvent } & \multirow{2}{*}{$\begin{array}{l}\text { Concentra- } \\
\text { tion }\end{array}$} & \multicolumn{3}{|c|}{${ }^{\nu} \mathrm{N}-\mathrm{H}$ bonded } & \multirow{2}{*}{$\begin{array}{l}\text { Number }{ }^{\mathrm{C}} \\
\text { of } \\
\text { H-bonds }\end{array}$} & \multicolumn{3}{|c|}{${ }^{\nu} \mathrm{N}-\mathrm{H}$ free } & \multirow{2}{*}{$\begin{array}{l}\text { Number } \\
\text { of free } \\
\mathrm{NH}\end{array}$} \\
\hline & & & $\begin{array}{l}\text { Position } \\
\left(\mathrm{cm}^{-1}\right)\end{array}$ & $\begin{array}{l}\Delta v_{1 / 2} \\
\left(\mathrm{~cm}^{-1}\right)\end{array}$ & $\begin{array}{l}\text { Inten- } \\
\text { sity } b\end{array}$ & & $\begin{array}{l}\text { Position } \\
\left(\mathrm{cm}^{-1}\right)\end{array}$ & $\begin{array}{l}\Delta v_{1 / 2} \\
\left(\mathrm{~cm}^{-1}\right)\end{array}$ & $\begin{array}{l}\text { Inten- } \\
\text { sity }\end{array}$ & \\
\hline $\mathrm{I}^{\mathrm{e}}$ & CHCI, & $5.75 \times 10^{-3}$ & 3385 & 21 & 0.152 & & 3437 & 18 & 0.287 & \\
\hline \multirow[t]{2}{*}{ II } & $\mathrm{CHCl}_{3}$ & $5.04 \times 10^{-3}$ & 3368 & 36 & 1.445 & 0.99 & 3434 & 24 & 0.686 & 1.1 \\
\hline & $\mathrm{CCl}_{4}$ & $1.0 \times 10^{-4}$ & 3388 & 24 & 0.906 & 1.08 & 3443 & 18 & 0.301 & 0.74 \\
\hline \multirow[t]{2}{*}{ III } & $\mathrm{CHCl}_{3}$ & $4.76 \times 10^{-3}$ & 3352 & 37 & 1.394 & 0.96 & 3435 & 23 & 0.665 & 1.0 \\
\hline & $\mathrm{CCl}_{4}$ & $1.06 \times 10^{-4}$ & 3368 & 28 & $\mathrm{I} .002$ & 1.19 & 3444 & 16.5 & 0.323 & 0.79 \\
\hline \multirow[t]{2}{*}{ IV } & $\mathrm{CHCl}_{3}$ & $4.90 \times 10^{-3}$ & 3344 & 44 & 2.901 & 2.0 & 3433 & 23 & 0.625 & 1.0 \\
\hline & $\mathrm{CCl}_{4}$ & $0.99 \times 10^{-4}$ & 3360 & 34 & 1.676 & 2.0 & 3441 & 18 & 0.405 & 1.0 \\
\hline \multirow[t]{2}{*}{ V-L } & $\mathrm{CHCl}_{3}$ & $4.74 \times 10^{-3}$ & 3332 & 51 & 4.922 & 3.39 & 3433 & 24 & 0.692 & 1.11 \\
\hline & $\mathrm{CCl}_{4}$ & $1.02 \times 10^{-4}$ & 3350 & 36 & 2.645 & 3.16 & 3442 & 17 & 0.244 & 0.60 \\
\hline VI-L & $\mathrm{CHCl}_{3}$ & $4.3 \times 10^{-3}$ & 3332 & 56 & 5.370 & 3.70 & 3432 & 25 & 0.562 & 0.90 \\
\hline VII & $\mathrm{CHCl}_{3}$ & $4.73 \times 10^{-3}$ & 3356 & 45 & 2.815 & 1.94 & 3424 & 25 & 1.104 & 1.77 \\
\hline V-D & CHCI, & $4.57 \times 10^{-3}$ & 3335 & 53 & 4.296 & 2.96 & 3432 & 23 & 0.666 & 1.07 \\
\hline VI-D & CHCI, & $4.88 \times 10^{-3}$ & 3332 & 52 & 6.008 & 4.14 & 3432 & 25 & 0.685 & 1.1 \\
\hline
\end{tabular}

a I Z-Aib-Pro-Ohle; II Z-Aib-Pro-NHMe; III Z-Aib-Pro-Aib-OMe; IV Z-Aib-Pro-Aib-Ala-OMe; V Z-Aib-Pro-Aib-Ala-Aib-OMe; VI Z-Aib-Pro-Aib-Ala-Aib-Ala-OMe; VII Z-Aib-Aib-Ala-NHMe;V-D Z-Aib-Pro-Aib-D-Ala-Aib-OMe; V1-D Z-Aib-Pro-Aib-D-Ala-AibAla-OMe

b Unit $\mathrm{mol}^{-1}$ liter $\mathrm{cm}^{-1} \times 10^{-4}$

c Calculated using a value of 2.0 for IV

d Calculated using a value of 1.0 for IV

e Number of hydrogen bonds not indicated as $\beta$-turn structnres are not possibte

Figure 3 shows a plot of the integral infrared intensities of the $3330-3370 \mathrm{~cm}^{-1}$ band as a function of the number of hydrogen bonds. A remarkably good correlation exists for II, III and IV whose conformations have been unambiguously established $[1,4,5]$. The model tripeptide amide Z-Aib-Aib-Ala$\mathrm{NHMe}_{3}$ (VII) is expected to possess 2 consecutive -Aib-Aib and -Aib-Ala- $\beta$-turns on the basis of the infrared data. This is in agreement with the established tendency of Aib residues to initiate $\beta$-turns, which has been conclusively demonstrated by the<smiles>CO[C@H]1CCCN1C(=O)C(C)(C)NC(C)=O</smiles>

fa)

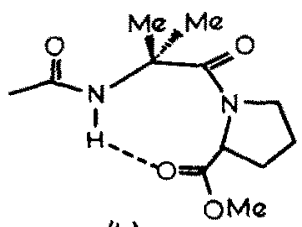

(b)

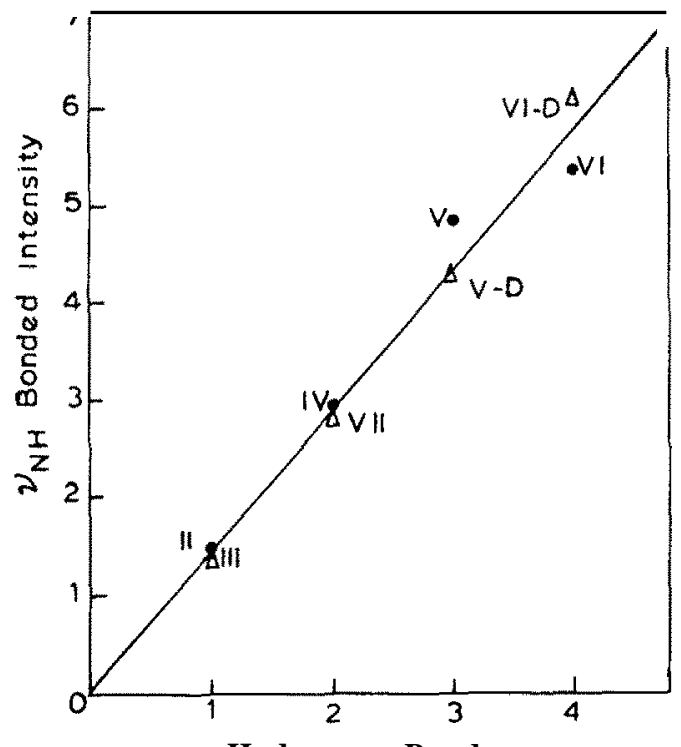

Hydrogen Bonds
Fig. 2. Possible hydrogen bonded structures for I. (a) 5 atom; (b) 8 atom.
Fig. 3, Plot of $v_{\mathrm{N}-\mathrm{H}}$ bonded band intensity as a function of the number of hydrogen bonds. 


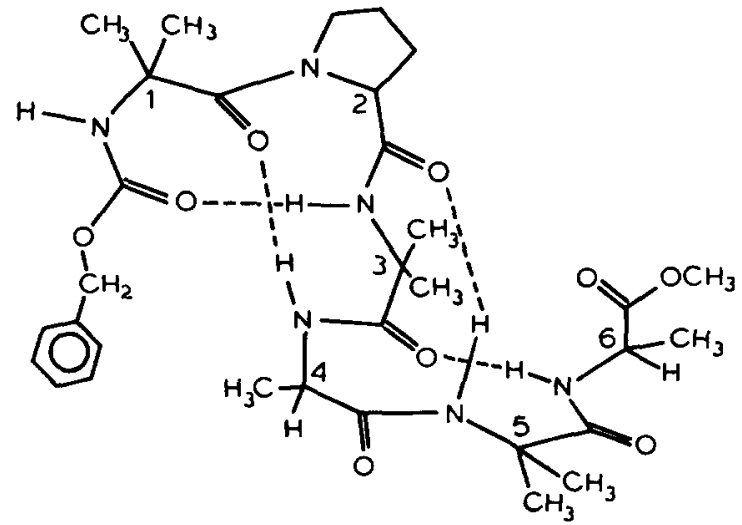

Fig.4. Schematic representation of the hydrogen bonded conformation of the hexapeptide VI.

$3_{10}$ helical conformation of Tosyl-(Aib) $5_{5}$-OMe, possessing 3 intramolecular hydrogen bonds [6]. The data in table 1 and fig. 3 further suggest that the amino-terminal penta (V) and hexapeptide (VI) of alamethicin contain 3 and 4 intramolecular hydrogen bonds. A schematic representation of a hexapeptide conformation involving 4 consecutive hydrogen-bonded $\beta$-turns is shown in fig.4.

Since Aib residues can adopt either right or left handed $3_{10}$ helical conformations $\left(\phi=-60^{\circ}, \psi=\right.$ $-30^{\prime \prime}$ and $\phi=+60^{\circ}, \psi=+30^{\circ}$ ) it was of interest to see the effect of changing the configuration of one of the optically active amino acids. Table 1 lists the infrared band intensities for the (D-Ala ${ }^{4}$ ) pentapeptide (V-D) and the (D-Ala ${ }^{4}$ ) hexapeptide (VI-D). It is seen that the change in configuration at position 4 is largely without effect on the number of intramolecular hydrogen bonds. This suggests that the right-handed folding of the polypeptide chain observed in the solid state for IV [5] is maintained in V-D and VI-D. Presumably the Pro ${ }^{2}$ residue dictates the sense of twist as $\phi=$ $+60^{\circ}$ is not possible for L-proline. On the other hand, D-Ala can indeed adopt values in the region $\phi=-60^{\circ}$, $\psi=-30 "$.

Infrared studies of the amino-terminal fragments of alamethicin reveal that a $3_{10}$ helical structure is nucleated in this part of the molecule. Further, -Aib-Pro- ,-Pro-X- and-Aib-X-sequences (where X is any amino acid) can be accommodated at the corners of type III (or type I) $\beta$-turns [18], as evidenced by the steady increase in the number of hydrogen bonds on going from II to VI. This provides strong support for our earlier contention that alamethicin may indeed adopt a largely $3_{10}$ helical structure [5]. While considerable evidence has accumulated for the formation of transmembrane channels by alamethicin [19], individual alamethicin molecules are unlikely to adopt helical conformations with large internal diameters. The closely related $3_{10}$ and $\alpha$-helical structures [20], which appear to be the conformations most accessible to alamethicin, are incapable of allowing passage of cations through the inside of the helix. Alamethicin aggregates have been implicated in its unique membrane activity [19]. The results of these structural studies suggest that the association of largely $3_{10}$ helical structures needs to be considered. The results presented here constitute the first clear demonstration of the systematic development of secondary structure in a growing polypeptide chain. The infrared technique outlined above provides a quick and reliable method of quantitating the number of hydrogen bonds in alamethicin fragments. This method may be used to advantage in studies of stereochemically constrained peptides, where the structures determined in the solid state also persist in solution. In order to test the predictions of the infrared method the crystal structures of Z-Aib-Aib-Ala-NHMe and the hexapeptide Z-Aib-Pro-Aib-Ala-Aib-Ala-OMeare currently under investigation.

\section{Acknowledgements}

R. N. thanks the Department of Atomic Energy for a scholarship. Financial support from the Department of Science and Technology is gratefully acknowledged.

\section{References}

[1] Nagaraj, R., Shamala, N. and Balaram, P. (1979) J. Am. Chem. Soc. in press.

[2] Marshall, G. R. and Bosshard, H. E. (1972) Circul. Res. 30 , suppl. II, $143-150$.

[3] Burgess, A. W. and Leach, S. J. (1973) Biopolyniers 12, 2599-2603.

[4] Venkataram Prasad, B. V., Shamala, N., Nagaraj, R., Chandrasekaran, R. and Balaram, P. (1979) Biopolymers, in press. 
[5] Shamala, N., Nagaraj, R. and Balaram, P. (1977) Biochem. Biophys. Kes. Commun. 79, 292-298.

[6] Shamala, N., Nagaraj, R. and Balaram, P. (1978) J. Chem. Soc. Chem. Commun. 996-997.

[7] Martin, D. R. and Williams, R. J. P. (1976) Biochem. J. 153,181- 190 .

[8] Pandey, R. C., Carter Cook, J., jr and Rinehart, K. L., jr (1977) J. Am. Chem. Soc. 99, 8469-8483.

[9] Pandey, R. C., Meng, H., Carter Cook, J.,jr and Rinehart, K. L., jr (1977) J. Am. Chern. Soc. 99, 5203--5205.

[10] Pandey, R. C., Carter Cook, J., jr and Rinehart, K. L., jr (1977) J. Am. Chern. Soe. 99, 5205-5206.

[11] Jung, G., Konig, W. A., Liebrritz, D., Ooka, T., Janko, K. and Boheim, G. (I 976) Biochim. Biophys. Acta 433, 164-181.

[12] Irrnscher, C., Bovermann, G., Boheim, G. and Jung, G. (1978) Biochim. Biophys. Acta 507, 470-484.
[13] Ramsay, D. A. (1952) J. Am. Chem, Soc. 74, 72-80.

[14] Aubry, A., Protas, J., Boussard, G., Marraud, M. and Neel, J. (1978) Biopolymers 17, 1693-1712.

[15] Avignon, M., Huong, P. V., Lascombe, J., Marraud, M. and Neel, J. (1969) Biopolyrners 8, 69-89.

[16] Marraud, M., Neel, J., Avignon, M. and Huong, P. V. (1970) J. Chim. Phys. 67, 959-964.

[17] IUPAC-IUB Commission on Biocliemical Nomenclature (1970) Biochemistry 9, 3471-3479.

[18] Venkatachalam, C. M. (1968) Biopolyniers 6, 1425-1436,

[19] Mueller, P. (1976) in Horizons in Blochemistry and Biophysics (Quagliariello, E. et al. eds) vol. 2. pp. $230-284$.

[20] Donohue, J. (1953) Proc. Natl. Acad. Sci. USA 39, $470-478$ 